\title{
Modelling and Simulation of a Fluidized Bed Reactor for Minimum Ammonium Nitrate and Reduction of NOx Emissions
}

Aysar Talib Jarullah"

Chemical Engineering Department, College of Engineering, Tikrit University, Salahuddin, Tikrit-34001, Iraq. Article Info: Submitted on March 10, 2018, Accepted on June 1, 2018.

\begin{abstract}
Due to the environmental legislations related to the nitrates and their emissions, thermal decomposition of ammonium nitrate (AN) in a fluidized reactor (FR) is regarded one of the most reasonable chemical-free disposal process for an aqueous waste nitrate stream. Therefore, the present study is aimed to improve a mathematical model based on experiments (from the literature) for enhancing the design of such reactor in an environmentally friendly manner. Where, the optimal kinetic parameters of the relevant reactions are firstly obtained employing the optimization technique keeping in mind the goal to construct the model with high exactness. Such design factors are then utilized for the purpose of getting the optimal operating conditions of fluidized bed reactor (FBR) achieving the main target of this process with ammonium nitrate-free content (Nil) at the end of the reactor in addition to reducing the $\mathrm{NO}_{x}$ emissions. The model is based on the two-phase theory of a FBR with predicting the concentration behavior along the reaction zone length for all components in the emulsion and bubble phases in addition to the temperature profile of the gas phase. New results related to output conversion of ammonium nitrate as well as NO content at the optimal operating conditions has been obtained in comparison with those reported in the literature.
\end{abstract}

Keywords: Ammonium nitrate decomposition; Thermal denitration; Fluidized bed; NOx emissions.

\section{Introduction}

In general, the production operation for regular uranium transformation typically starts with yellowcake disintegration in nitric acid then by a dissolvable extraction operation. The nuclear-pure uranyl nitrate mixture obtained via solvent extraction will be carried out with $\mathrm{NH}_{3}$ for precipitating the uranium as ammonium diuranate (ADU) followed by filtration process in order to separate precipitated ADU. The ADU obtained having ammonium nitrate (AN) in addition to small amounts of radioactive contaminants and such liquid stream is posed as a disposal problem owing to the high concentration of nitrate leading to harmful biological impacts in addition to the inevitability of its entering drinking water sources causing cancer and other diseases ${ }^{1-3}$. Owing to the excessive utilize of fertilizers in crops, septic tanks, livestock, and sewage waste containing nitrates, the environmental regulations have become more strict during the last years related to such impurities facing mankind ${ }^{1,2,4}$. Nowadays, the most serious issues generated by the discharge of nitrates components into the environment are the rivers eutrophication, hazards to human health and deterioration of water sources ${ }^{5}$.

The allowed quantity of nitrate in drinking water should not be exceeded $50 \mathrm{~g} / \mathrm{m}^{3}$ and $25 \mathrm{~g} / \mathrm{m}^{3}$ based on the World Health Organization (WHO) and the
European Community, respectively ${ }^{2}$. Thus, reducing the amount of nitrates before discharging process is an important issue. The rising pattern of nitrate quantities prompt an emphasis on the denitrification operation as the most eff icient techniques for its in situ elimination, where the nitrate is converted to $\mathrm{N}_{2}$ gas and expelled from $\mathrm{H}_{2} \mathrm{O}$. Several advances methods have been created for denitrification to treat the issue of ammonium nitrate in drinking water or wastewater, such as bioelectrochemical systems, membrane reactors, fixed and fluidized-bed reactors 6-11. Fluidized-bed thermal denitration (FBTD) is regarded as a proper technique for treating such waste nitrate streams created in the nuclear fuel cycle. This chemical free treating alternative is environmentally considerate for the transfer of watery waste nitrate streams, where the nitrate stream is showered into a hot fluidized bed and the bed is kept up at the required temperature via acceptable warming framework. In this procedure, AN decays dominatingly into $\mathrm{N}_{2}, \mathrm{O}_{2}$, and $\mathrm{H}_{2} \mathrm{O}$ in addition to small amount of $\mathrm{NO}_{\mathrm{x}}{ }^{1}$.

AN as a significant fertilizer with $34 \% \mathrm{~N}_{2}$, is another general source of nitrates in soil and explosive materials and due to its high dissolvability in $\mathrm{H}_{2} \mathrm{O}$. It is a reason for groundwater pollution, which is likewise present in an industrial wastewater. 


\section{Chemical Engineering Research Bulletin 20(2018) 8-18}

According to the reasons mentioned above, several studies related to the thermal decomposition of AN have recently been reported in the literature on FBTD technology. Bhowmick et al. (2012) ${ }^{1}$ have developed a mathematical model of AN thermal decomposition in a fluidized bed reactor based on experiments and studying the impacts of different process factors on process conversion. The authors have compared the model predictions with pilot plant experimental results and they found that the model predictions were agreement with the experimental results. Optimum values of operating parameters for maximizing the conversion have also been investigated.

Mirvakili et al. (2013) ${ }^{2}$ have studied a conventional thermal decomposition of ammonium nitrate in a FBR, and in two cascading fixed-bed and fluidized-bed dual reactors (CFFDRs) connected in series. Where, ammonium nitrate thermal decomposition happens in the $1^{\text {st }}$ reactor (FR) giving NOx, whereas a selective catalytic reaction reducing NO with ammonia occurs in the $2^{\text {nd }}$ reactor. Minimizing of ammonium nitrate and $\mathrm{NO} x$ were taken into accounts based on the optimal operating conditions for the proposed CFFDR. Mirvakili et al. (2014) ${ }^{12}$ proposed a mathematical model including two configurations called membrane fluidized bed reactor (MFR) and free air membrane fluidized bed reactor (AMFR) to decrease NOx emission. They found that the amount of NOx can be reduced by $16 \%$ and $7 \%$ using AMFR and MFR, respectively in comparison with those obtained by the conventional FR process. Mirvakili et al. (2015) ${ }^{3}$ have studied the optimal operating conditions of AN thermal decomposition via differential evaluation (DE) technique to reduce the quantity of AN at the outlet of the reactor. The model consists of two-phase theory of a bubbling FR, and predicting the axial behavior of all compounds in the emulsion and bubble phases in addition to axial temperature behavior of the gas phase. The results predicted showed agreement with the experimental data introduced by Bhowmick et al. (2012) ${ }^{1}$. They demonstrated that the AN content increased gradually along the reactor by decreasing the reaction temperature and the gas velocity. Although most of the previous studies have developed a mathematical model to characterize the FBTD of AN, there are still some significant issues should be investigated. Thus, the main focus of this study is firstly improving the kinetic parameters of ammonium nitrate thermal decomposition (ANTD) based on the experimental data obtained from the literature (which are previously ignored or kept constant). Where, the model presented is firstly investigated by utilizing the optimization technique to get the optimal kinetic parameters with a high accuracy based on average absolute error less than $1 \%$ among all results and obtaining a high agreement between plant data and the model results. Secondly, the optimal operating conditions are investigated utilizing the model generated for the purpose of minimizing the concentration of ammonium nitrate and $\mathrm{NO} x$ emissions. Where, the traditional ANTD takes place in a FR at high temperature leads to generate a considerable quantity of NO. Therefore, the second optimization process is employed to achieve an environmentally friendly reactor with a complete output conversion of ammonium nitrate at such optimal conditions (nil) and minimum amount of NO.

\section{Process Description of AN Reactor}

A conventional fluidized reactor is generally used for ANTD. The bed of the reactor is stuffed with sands, where the heating system coming from the outside of the reactor is used to heat the sands. A layout sketch of FBR for ANTD is illustrated in Figure 1. The sands inside the reactor are fluidized via hot air coming from the bottom of the reactor and the liquid stream comprised of AN sprays into the fluidized bed reactor. Consequently, a thermal chemical reaction of ammonium nitrate deterioration is completed without a catalyst, takes place overwhelmingly on the hot surface of sands.

Actually, the fluid droplets are adsorbed on the hot surface of the emulsion particles to be vaporized afterwards. Since the rate of heat exchange from the particles to the stored droplets is high, water dissipation and volatilization of $\mathrm{AN}$ reactions are finished in the spray section. Likewise, NOx as an undesired compound generated during the thermal decomposition of ammonium nitrate in the presence of created $\mathrm{N}_{2}$ and $\mathrm{O}_{2}$ and the hot air in the fluidized reactor.

\section{Experimental Data}

The experimental results of ammonium nitrate thermal decomposition have taken from Bhowmick et al. (2012) 1. A brief description about the apparatus, materials and experimental procedure utilized to obtain the experimental data is summarized as follows: a series of experiments were conducted to investigate the impacts of different process factors upon the conversion of AN.

To study the effect of a special operation factor, such parameter has varied over a range with keeping other factors constant. In the FBR, the feed nozzle was situated over a distributor slanted downward. In the pilot plant system, it has been calculated that the droplets deposition have practically finished under the situation of the spray nozzle. The amount of heat transfer generated by the particles to the kept beads was high to the point that $\mathrm{H}_{2} \mathrm{O}$ dissipation and volatilization of AN were finished in the spray zone. Based on this point, the bed accessible over the spray 


\section{Chemical Engineering Research Bulletin 20(2018) 8-18}

nozzle was regarded as the reaction zone. The experimental information for ammonium nitrate thermal decomposition utilized for modelling evaluations in this study is presented in Table 1 below.
For more details related to the reactor configurations and pilot plant information can be found in Bhowmick et al. (2012) ${ }^{1}$.

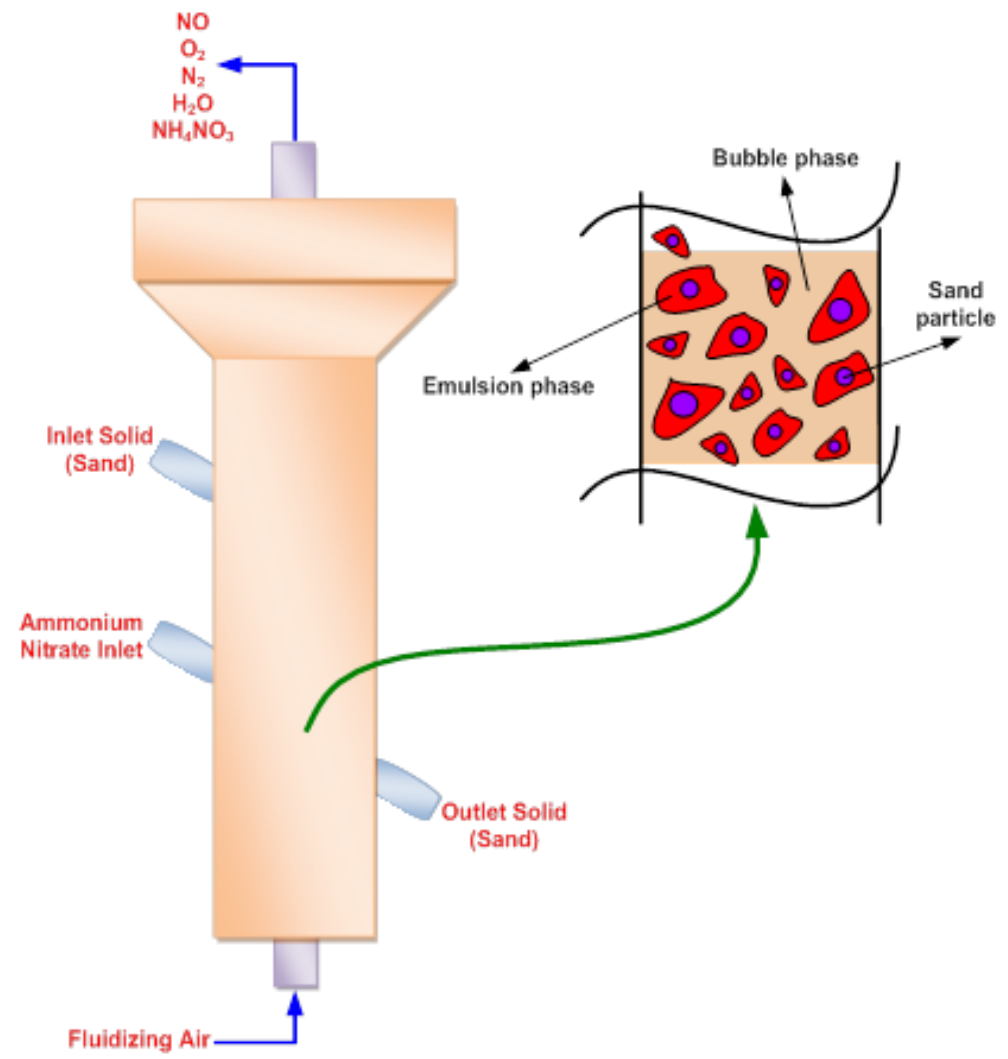

Figure 1: Layout sketch of FBR for ammonium nitrate thermal decomposition

Table 1: Experimental data employed for modelling evaluations ${ }^{1}$

\begin{tabular}{|c|c|}
\hline Property & Values \\
\hline \multicolumn{2}{|c|}{ Feedstock } \\
\hline Inlet concentration of ammonium nitrate & $150\left(\mathrm{~kg} / \mathrm{m}^{3}\right)$ \\
\hline Inlet concentration of nitrogen & $142.2\left(\mathrm{~kg} / \mathrm{m}^{3}\right)$ \\
\hline Inlet concentration of nitrogen oxide & 0.0 \\
\hline Inlet concentration of oxygen & $37.8\left(\mathrm{~kg} / \mathrm{m}^{3}\right)$ \\
\hline Inlet concentration of water & 0.0 \\
\hline \multicolumn{2}{|c|}{ Fluidized Bed Reactor } \\
\hline Fluidized bed height & $0.6(\mathrm{~m})$ \\
\hline Bed diameter & $0.15(\mathrm{~m})$ \\
\hline Mean sand size & $3 \times 10^{-4}(\mathrm{~m})$ \\
\hline Sand density & $2600\left(\mathrm{~kg} / \mathrm{m}^{3}\right)$ \\
\hline \multicolumn{2}{|c|}{ Operating Conditions } \\
\hline Bed temperature & $350{ }^{\circ} \mathrm{C}$ \\
\hline Fluidizing air flow & $2 \mathrm{U}_{\mathrm{m}}$ \\
\hline Feed flow rate & $0.006\left(\mathrm{~m}^{3} / \mathrm{h}\right)$ \\
\hline Gas to liquid ratio & 1.2 \\
\hline
\end{tabular}




\section{Chemical Engineering Research Bulletin 20(2018) 8-18}

\section{Mathematical Modeling of AN Reactor}

Constructing models is one of the genuine occupations of designing and engineering science. Models are utilized in light of the fact that it is excessively costly, tedious or hazardous to utilize genuine framework to assess plant execution. Models are normally utilized in building outline and optimal operations since they offer the least expensive and speedier method for investigating the effects of changes in plan factors on system behavior. A basic point in the change of any model is the development of the proper material and energy balance correlations. To these ought to be included reasonable kinetic relations of chemical reaction rates, amount of mass and energy balance and correlations representing process specifications.

The essential scientific model can be given by blend of these ${ }^{13,14}$. In this work, a heterogeneous onedimensional mathematical model involves a series of coupled energy and mass balances, reaction rate equations, mass and heat transfer coefficients and hydrodynamic parameters of ammonium nitrate thermal decomposition is taken into account.

\section{Mass Balance in the Bubble Phase}

The mass balance equations along the reaction zone length for ammonium nitrate (AN), nitrogen oxide $(\mathrm{NO})$, nitrogen $\left(\mathrm{N}_{2}\right)$, oxygen $\left(\mathrm{O}_{2}\right)$ and water $\left(\mathrm{H}_{2} \mathrm{O}\right)$ in the bubble phase can be written as follows:

$$
\frac{d C_{i}^{B}}{d l}=\frac{A_{C}}{v_{i}} \cdot k_{i}^{B E} \cdot\left(C_{i}^{E}-C_{i}^{B}\right)+\frac{A_{C}}{v_{i}} \cdot \sum_{j=1}^{2} R_{i j}^{B}
$$

\section{Mass Balance in the Emulsion Phase}

The mass balance equations along the reaction zone length for $\mathrm{AN}, \mathrm{NO}, \mathrm{N}_{2}, \mathrm{O}_{2}$ and $\mathrm{H}_{2} \mathrm{O}$ in the emulsion phase are described as follows:

$$
\frac{d C_{i}^{E}}{d l}=\frac{\alpha \cdot A_{C}}{v_{i} \cdot(1-\alpha)} \cdot k_{i}^{B E} \cdot\left(C_{i}^{B}-C_{i}^{E}\right)+\frac{A_{C}}{v_{i}} \cdot \sum_{j=1}^{2} R_{i j}^{E}
$$

\section{Energy Balance of the Reaction Zone}

The differential heat balance equation that has taken into consideration along the reaction zone.

$$
\begin{aligned}
& \frac{d T}{d l}=\frac{M w_{i}}{m s_{i} \cdot C_{p}} \cdot A_{C} \cdot(1-\alpha) \cdot \sum_{j=1}^{2} R_{i j}^{E} \cdot\left(-\Delta H_{j}^{f}\right)+\alpha . \\
& A_{C} \cdot \frac{M w_{i}}{m s_{i} \cdot C_{p}} \sum_{j=1}^{2} R_{i j}^{B} \cdot\left(-\Delta H_{j}^{f}\right)
\end{aligned}
$$

In all sections presented above, $i=\mathrm{AN}, \mathrm{NO}, \mathrm{N}_{2}, \mathrm{O}_{2}$ and $\mathrm{H}_{2} \mathrm{O}$

\section{Chemical Reaction Rates}

In the FBR, there are two main reactions can simultaneously be taken place: AN decomposition and NO formation. Decomposition of $\mathrm{AN}$ is an exothermic reaction whereas the reaction of $\mathrm{NO}$ is endothermic. Note that, Bhowmick et al. (2012) ${ }^{1}$ have only taken into accounts the mass balance for ammonium nitrate. Such chemical reactions are as follows ${ }^{1-3}$ :

$$
\begin{aligned}
& \mathrm{NH}_{4} \mathrm{NO}_{3} \rightarrow \mathrm{N}_{2}+1 / 2 \mathrm{O}_{2}+2 \mathrm{H}_{2} \mathrm{O} \\
& (\Delta \mathrm{Hrxn}=-118.86 \mathrm{~kJ} / \mathrm{mol}) \\
& \mathrm{O}_{2}+\mathrm{N}_{2} \rightarrow 2 \mathrm{NO} \\
& (\Delta \mathrm{Hrxn}=90.4 \mathrm{~kJ} / \mathrm{mol})
\end{aligned}
$$

The chemical reaction rate equation for AN thermal decomposition can be described using the following equation:

$$
R_{A N}=k_{A N} \cdot C_{A N}^{n}
$$

Reaction rate constant for AN thermal decomposition reaction $\left(K_{A N}\right)$ can be calculated utilizing the Arrhenius equation as follows:

$$
K_{A N}=A_{A N}^{0} \exp \left(-\frac{E A_{A N}}{R T}\right)
$$

The main difference of the kinetic equation in this study with those reported in the literatures is the estimation of the kinetic parameters related to this reaction. Where, the authors in the public domain have assumed that the reaction order of AN compound $(n)$ follows first order reaction with the activation energy $\left(E A_{A N}\right)$ and pre-exponential factor $\left(A^{0}{ }_{A N}\right)$ reported by Bhowmick et al. (2012) ${ }^{1}$. Thus, The major point of this study is to accurately calculate these parameters employing the optimization technique based on experiments presented by Bhowmick et al. (2012) ${ }^{1}$ to reduce the errors between the experimental and predicted results as low as possible, which is the first case study of this work.

The chemical reaction rate equation for nitrogen oxide formation, which is ignored by Bhowmick et al. (2012) ${ }^{1}$ have taken into consideration in this study and can be written as ${ }^{15}$ :

$$
R_{N O}=1.32 \times 10^{10} \cdot C_{N_{2}} \cdot C_{O_{2}}^{0.5} \cdot \operatorname{Exp}\left(\frac{-545000}{\mathrm{R} \cdot \mathrm{T}}\right)
$$

\section{Mass and Heat Transfer Coefficients and Hydrodynamic Parameters}

The correlations used for calculating the overall mass transfer coefficient with their parameters are ${ }^{1,3,12,16-}$ 19:

$\frac{1}{k^{B E}}=\frac{1}{k^{B C}}+\frac{1}{k^{C E}}$ 


\section{Chemical Engineering Research Bulletin 20(2018) 8-18}

$k^{B C}=\frac{4.5 \cdot u_{m f}}{d_{B}}+\frac{5.85 \cdot D_{i m}^{0.5} \cdot g^{0.25}}{d_{B}^{1.25}}$

$k^{C E}=\frac{6.77 \cdot D_{i m} \cdot \varepsilon_{m f} \cdot\left(0.711 \cdot\left(g \cdot d_{B}\right)^{0.5}\right)}{d_{B}^{3}}$

The superficial velocity at minimum fluidization $\left(u_{m f}\right)$ can be calculated as $1,2,12$ :

$u_{m f}=\frac{\mu_{g} \cdot\left(\left(739.84+0.0408 \cdot A_{r}\right)^{0.5}-27.2\right)}{\rho_{g} \cdot d_{p}}$

$A r=\frac{\rho_{g} \cdot d_{p}^{3} \cdot g \cdot\left(\rho_{p}-\rho_{g}\right)}{\mu_{g}^{2}}$

The bed voidage at minimum fluidizing conditions can be calculated employing the following relation ${ }^{1}$, 19.

$$
\begin{aligned}
& \varepsilon_{m f}=\frac{0.3507 \cdot A r^{0.0337}}{\operatorname{Re}_{m f}^{0.0704}} \\
& \operatorname{Re}_{m f}=\frac{\rho_{g} \cdot u_{m f} \cdot d_{p}}{\mu_{g}}
\end{aligned}
$$

The average bubble size (bubble diameter) at bed height $\mathrm{z}\left(d_{B}\right)$ is determined using the following equation ${ }^{1,20}$ :

$d_{B}=0.21 \cdot z^{0.8} \cdot\left(u_{g}-u_{m f}\right)^{0.42} \cdot \operatorname{Exp}\left(-0.25 \cdot\left(u_{g}-u_{m f}\right)^{2}\right.$

$\left.-0.1 \cdot\left(u_{g}-u_{m f}\right)\right)$

The bubble phase fraction to the overall bed $(\alpha)$ presented in equations 2 and 3 above can be describes as (Bhowmick et al. (2012) ${ }^{1}$; Mirvakili et al. $(2013)^{2},(2015)^{3}$ :

$\alpha=\frac{u_{g}-u_{m f}}{u_{b}}$

While the bubble rise velocity $\left(u_{b}\right)$ is stated as follows 1,21 :

$u_{b}=u_{g}-u_{m f}+0.711 \cdot \sqrt{g \cdot d_{B}}$

The molecular diffusivity of component $i$ in the mixture with the diffusion coefficients of component $i$ in component $j$ and their factors can be estimated utilizing the following equations $1,2,12,16,22$ :

$$
\begin{aligned}
D_{i m}= & 1-x_{i} / \sum_{\substack{j=1 \\
j \neq 1}}^{n} \frac{x_{i}}{D_{i j}} \\
D_{i j} & =\frac{T^{0.5} \cdot\left(0.00303-\frac{0.00098}{M_{i j}^{0.5}}\right)}{M_{i j}^{0.5} \cdot P \cdot \sigma_{i j}^{2} \cdot \Omega_{D}}
\end{aligned}
$$

$$
\begin{aligned}
& M_{i j}=\frac{2}{\left(\frac{1}{M_{i}}\right)+\left(\frac{1}{M_{j}}\right)} \\
& \sigma_{i j}=\frac{\sigma_{i}+\sigma_{j}}{2} \\
& \Omega_{D}=\frac{1.06036}{\mathrm{~T}_{*}^{0.15610}}+\frac{0.19300}{\operatorname{Exp}\left(0.47635 \cdot \mathrm{T}_{*}\right)}+ \\
& \frac{1.03587}{\operatorname{Exp}\left(1.52996 \cdot \mathrm{T}_{*}\right)}+\frac{1.76474}{\operatorname{Exp}\left(3.89411 \cdot \mathrm{T}_{*}\right)} \\
& \mathrm{T}_{*}=T \cdot\left(\frac{\kappa}{\varepsilon_{i j}}\right) \\
& \frac{\varepsilon_{i j}}{\kappa}=\left(\frac{\varepsilon_{i}}{\kappa} \cdot \frac{\varepsilon_{j}}{\kappa}\right)^{0.5}
\end{aligned}
$$

For each component ${ }^{16}$,

$$
\begin{aligned}
& \sigma=1.18 \cdot V_{b}^{1 / 3} \\
& \frac{\varepsilon}{\kappa}=1.15 \cdot T_{b}
\end{aligned}
$$

\section{Case Studies}

Case 1: Employing of an appropriate model is useful not only in enhancing operation investigation and in optimizing operation process conditions, yet in addition in the design of the control methodologies for the operation under consideration. A key issue, notwithstanding, in the improvement of operation models whether steady state or dynamic, is parameter calculation ${ }^{23,24}$. Thus, minimizing of the sum of the squared errors (SSE) between the experimental amounts of AN and estimated in the product at different temperatures as well as along a reaction zone components is utilized as an objective function in the optimization process for case 1 here in order to evaluate the optimal decision variables, which is ignored in the literature in this area. Non-linear regression is used to optimize the control variables (Reaction order $(n)$, Activation energy $\left(E A_{A N}\right)$ and Frequency factor $\left.\left(A^{0}{ }_{A N}\right)\right)$ simultaneously based on the average absolute error that should not be exceed $1 \%$ among all results. The following relation is used for this issue:

$S S E=\sum_{i=1}^{N}\left(C_{i}^{e x p}-C_{i}^{c a l}\right)^{2}$

Case 2: The optimal kinetic parameters obtained by case 1 are then applied in case study 2 to generate the optimal operating conditions via optimization process for the purpose of getting an environmentally friendly reactor (which is the main goal of this work) with a minimum concentration of $\mathrm{AN}$ and $\mathrm{NO}$ at such optimal conditions (nil or $\mathrm{AN}$-free content) in the 


\section{Chemical Engineering Research Bulletin 20(2018) 8-18}

product. In this case, minimizing $\mathrm{AN}$ as well as NO concentrations in the outlet of a fluidized reactor is regarded in the objective function described as follows:

$$
O B J=C_{A N}^{o u t}+C_{N O}^{o u t}
$$

Three design variables involving the bed temperature $(T)$, the gas velocity $\left(u_{g}\right)$, and the initial concentration of $\mathrm{AN}\left(C_{A N O}\right)$ are investigated during the optimization process. The temperature has chosen owing to its changes along a fluidized reactor and having a direct impact upon the reaction rates as well as controls the thermodynamic equilibrium. In other words, an increase in the gas velocity, the heat and mass transfer coefficients in addition to mixing degree will be increased giving an important influence on the reaction rates. Also, the output concentration of AN is a function of its initial concentration. The upper and lower bounds of the bed temperature is varied from 307 to $407{ }^{\circ} \mathrm{C}$, the gas velocity ranges between $2 \mathrm{u}_{\mathrm{mf}}$ to $7 \mathrm{u}_{\mathrm{mf}}$, and the initial concentration of $\mathrm{AN}$ should be between 75 to $200 \mathrm{~kg} / \mathrm{m}^{3}{ }^{1-3}$. The differential and algebraic equations presented above have utilized for the modelling of a fluidized reactor for ammonium nitrate thermal decomposition. The optimization problem is posed as a Non-Linear Programming (NLP) problem and is solved using a Successive Quadratic Programming (SQP) method to solve these set of equations for both cases.

\section{Optimization Problem Formulation}

Mathematically, the optimization problem for case 1 is stated as:

$$
\begin{aligned}
& \text { Min } S S E \\
& n, E A_{A N}, A^{0}{ }_{A N} \\
& \text { Subject to } y(w, m(w), u(w), g(w), q)=0, \\
& n^{L} \leq n, \leq n \\
& E A_{A N}{ }^{L} \leq E A_{A N} \leq E A_{A N}{ }^{U} \\
& A^{0}{ }_{A N}{ }^{L} \leq A^{0}{ }_{A N} \leq A^{0}{ }_{A N}{ }^{L} \\
& C_{A N}{ } \leq C_{A N} \leq C_{A N}{ }^{U}
\end{aligned}
$$

Whereas, the optimization problem for case 2 can be described as:

$$
\begin{array}{lc}
\text { Min } \quad \text { OBJ } & \\
C_{A N O}, T, u_{g} & \\
\text { Subject to } & y(w, m(w), u(w), g(w), q)=0, \\
& C_{A N O}{ }^{L} \leq C_{A N O} \leq C_{A N O} \\
T^{L} \leq T \leq T^{U} \\
u_{g}{ }^{L} \leq u_{g} \leq u_{g}{ }^{U} \\
C_{A N}{ }^{\text {out }} \leq C_{A N}{ }^{\text {out }} * \\
C_{N O}{ }^{\text {out }} \leq C_{N O} \text { out }
\end{array}
$$

$y(w, m(w), u(w), g(w), q)=0$ describes the system model presented above, where $w$ is the independent variable, $u(w)$ are the derivative of differential variables with respect to bed length, $m(w)$ represents the set of all differential and algebraic variables, $q$ gives the design variables, and $g(w)$ is the control variables. $\mathrm{L}$ and $\mathrm{U}$ is the lower and upper bound, respectively and $*$ is the target value.

\section{Results and Discussion}

\section{Optimal Kinetic Parameters (Case 1)}

The kinetic parameters of ammonium nitrate thermal decomposition considered in this work has been investigated here and estimated based on experimental data. Where, the reaction order $(n)$ of AN decomposition, activation energy $\left(E A_{A N}\right)$ and Frequency factor $\left.\left(A^{0}{ }_{A N}\right)\right)$, introduced by Bhowmick et al. (2012) ${ }^{1}$ have been modified and estimated simultaneously utilizing the optimization process for the purpose of getting the best kinetic model of the relevant reaction and improving such design parameters. The optimal kinetic parameters obtained for this case utilizing non-linear approaches are reported in Table 2 below:

Table 2: Optimal results for case study 1

\begin{tabular}{|l|c|}
\hline \multicolumn{1}{|c|}{ Parameters } & Optimal Values \\
\hline Reaction order $(n)$ & $0.968367(-)$ \\
\hline Activation energy $\left(E A_{A N}\right)$ & $88853.3(\mathrm{~J} / \mathrm{mol})$ \\
\hline Frequency factor $\left(A^{0}{ }_{A N}\right)$ & $\begin{array}{c}2.76089 \times 10^{6} \\
\left(\left(\mathrm{~mol} / \mathrm{m}^{3}\right)^{1-\mathrm{n}} \cdot \mathrm{s}^{-1}\right)\end{array}$ \\
\hline Sum of square errors $(S S E)$ & $0.8066(-)$ \\
\hline
\end{tabular}

As can be seen from Table 2 depending on the objective function and as illustrated in Figure 2 and 3 , the modified kinetic parameters obtained here is the lowest and more accurate compared with those reported in the literature among all the results ${ }^{1-3,12}$. The comparison between the experimental results (presented by Bhowmick et al. (2012) ${ }^{1}$ ) and model predictions obtained by this study (utilizing the modified design parameters) as well as last studies is shown in Figure 2 (at different reactor bed temperatures) and Figure 3 (at different reactor zone length). It can be reported that assuming a constant order reaction (which is $1^{\text {st }}$ order applied by last studies) of ammonium nitrate decomposition, and determining of activation energy and frequency factor via linearizing the Arrhenius equation giving larger error in comparison with simultaneous estimation of kinetic parameters by non-linear (NLN) method. Therefore, it has been noticed depending on these Figures, the model was found to predict the behavior of the fluidized reactor for AN reaction very well correspondence in the range of operation variables with average absolute error (AAE) less than $1 \%$ (among all the results of the ammonium nitrate conversion). 


\section{Chemical Engineering Research Bulletin 20(2018) 8-18}

In light of the outcomes exhibited over, a clear indication is noted where the behavior of the process can now confidently be predicted with high trusted for further insight of such process.

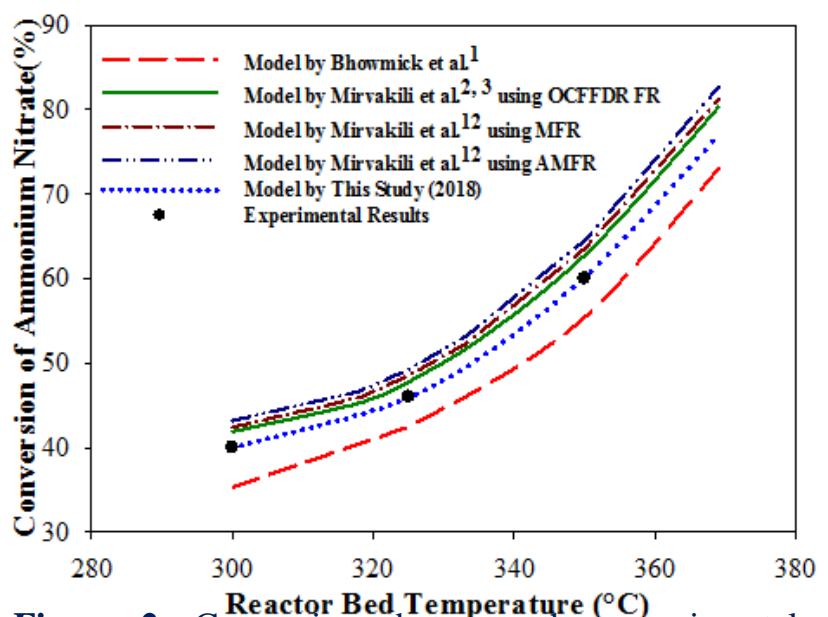

Figure 2: Comparison between the experimental results and model results obtained by this study and previous studies at different reactor bed temperature

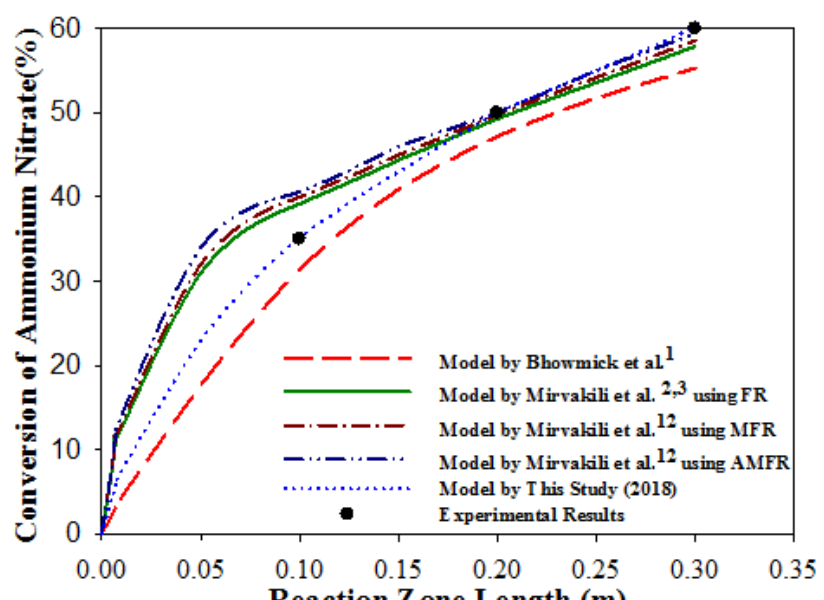

Figure 3: Comparison between the experimental results and model results obtained by this study and previous studies along reaction zone length

\section{The Behavior of the Fluidized Reactor}

The improved model can now be utilized to simulate the behavior of the fluidized reactor for ammonium nitrate thermal decomposition including the temperature profile as well as the concentration profile for each component in bubble and emulsion phase along the reaction zone length.

The temperature profile along the reaction zone length is illustrated in Figure 4. As can be seen from this Figure, the temperature is equivalent to the spray-zone temperature at the first section of the reaction zone. Where, a jump of temperature is noted since the reaction is highly exothermic giving an important heat generation of AN decomposition. Then, since the reaction rate of $\mathrm{AN}$ disintegration diminishes continuously and furthermore nitrogen oxide formation, which is an endothermic reaction, happens in the bed, the temperature diminishes steadily along the reaction zone length within fluidized reactor. Actually, the reaction rate of NO decreased due to the endothermic reaction leading to increase the bed temperature. Such increase in the temperature leads to high reaction rate of $\mathrm{AN}$ decomposition giving low concentration of $\mathrm{AN}$ content in the product.

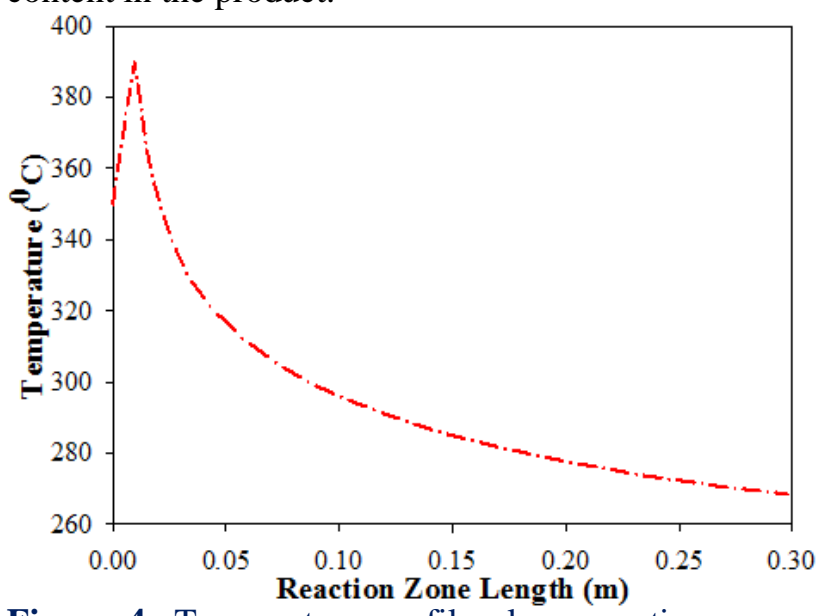

Figure 4: Temperature profile along reaction zone length

The concentration profile of $\mathrm{AN}$ in emulsion and bubble phase along reaction zone length is shown in Figure 5. As foreseeable, the initial concentration of $\mathrm{AN}$ in the emulsion phase is genuinely high based on the results showed in this Figure. The gas speed in the bubble phase that is precisely twice its base fluidization speed, is higher than the one in the emulsion phase; in this way, the contact time is high in the emulsion phase.

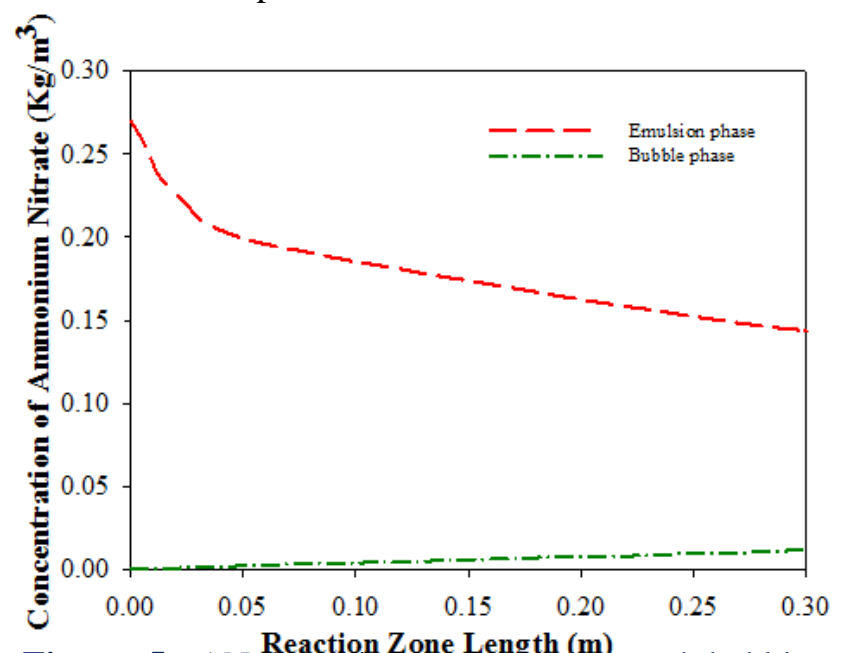

Figure 5: AN beaction Zone Length (m) phase along reaction zone length

Also, as the gas temperature in the bubble phase is less prominent than the temperature of the emulsion particles, ammonium nitrate deterioration happens in the emulsion phase and is significantly higher than the one in the bubble phase. As appeared in Figure 5, 


\section{Chemical Engineering Research Bulletin 20(2018) 8-18}

the initial concentration of AN is zero in the bubble phase due to a moderately low rate of mass exchange between bubble and emulsion phases that implies just a little amount of AN vapour in the emulsion phase is moved to the bubble phase. As specified already, the contact time and the temperature in the emulsion phase are higher than those in the bubble phase. In this manner, these variables prompt irrelevant decay of AN in the bubble phase and the AN enters and leaves the bubble phase bed with no conversion. As presented in Figure 5, the grouping of AN diminishes discernibly in the beginning section of the fluidized reactor, whereas there is a gradually diminishing pattern in whatever remains of the reactor. As well as, more deterioration of AN happens in this area owing to the high mass transfer coefficients in addition to the high blending rate toward first part of a fluidized reactor.

Figure 6 illustrates the concentration profile of $\mathrm{NO}$ in the emulsion phase and bubble phase along the fluidized bed reactor that increments progressively in such phases. Nitrogen oxide is considered a primary contaminant of the climate in addition to generating of acidic rain. NO generation occurs in the emulsion phase mostly, so the mass exchange happens between the emulsion and bubble phases as well as NO will be moved to the bubble phase. Owing to increasing the concentration of $\mathrm{N}_{2}$ and $\mathrm{O}_{2}$ along the fluidized bed reactor in bubble phase, the rate of mass transfer of nitrogen oxide generation is lower than those between the emulsion and bubble phases.

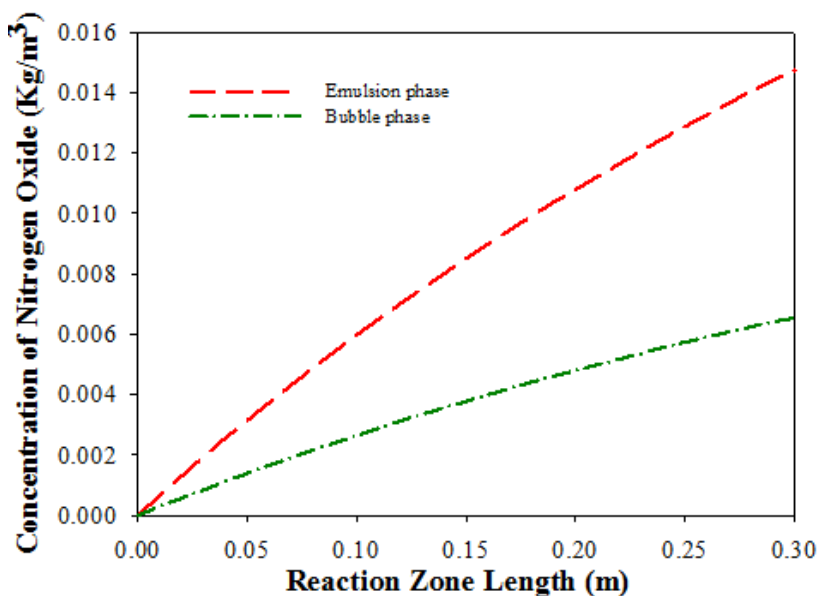

Figure 6: NO behaviors in emulsion and bubble phase along reaction zone length

The concentration profiles of $\mathrm{O}_{2}, \mathrm{~N}_{2}$ and $\mathrm{H}_{2} \mathrm{O}$ along the reaction zone length in bubble and emulsion phases are shown in Figures 7, 8 and 9, respectively. As can be observed from these Figures, the concentration profile of $\mathrm{O}_{2}$ and $\mathrm{N}_{2}$ having the same behavior.

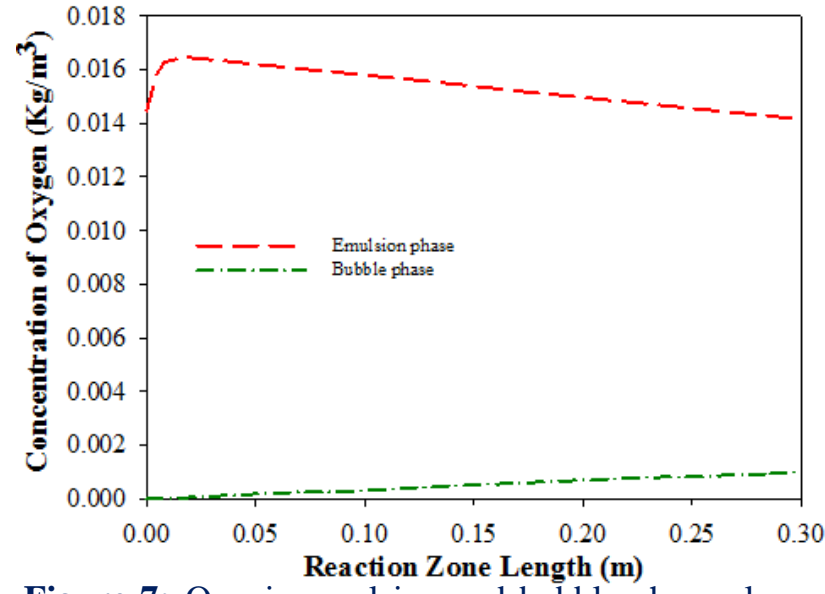

Figure 7: $\mathrm{O}_{2} \mathrm{~s}$ in emulsion and bubble phase along reaction zone length

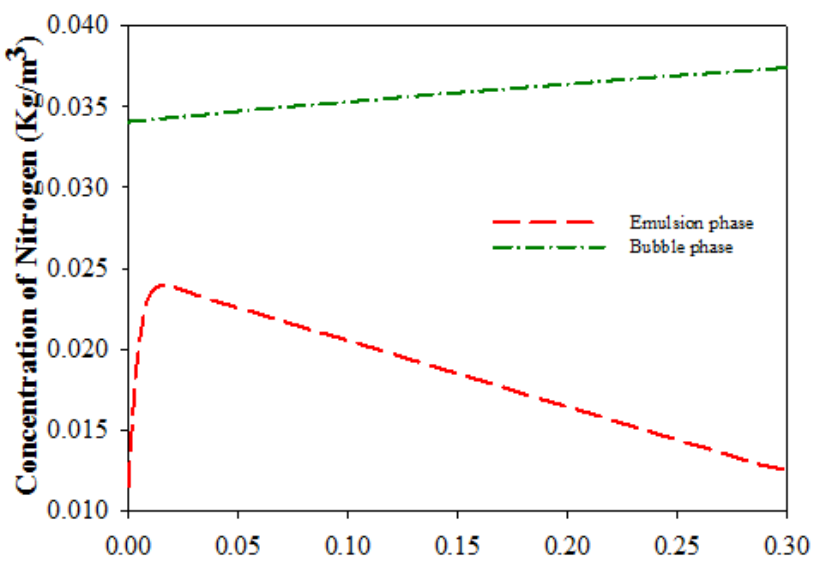

Figure 8: $\mathrm{N}_{2} \mathrm{~s}$ in Reaction Zone Length ${ }^{(m)}$ endion and bubble phase along reaction zone length

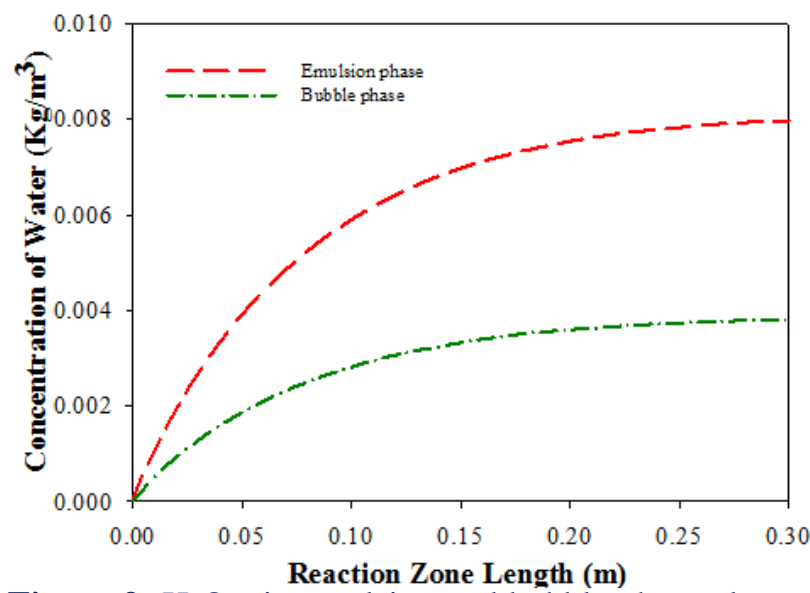

Figure 9: $\mathrm{H}_{2} \mathrm{O} \mathrm{s}$ in emulsion and bubble phase along reaction zone length

Such trend is attributed to AN decomposition reaction and both of them are generated and then will be consumed forming NO. At a first part of the reaction zone, $\mathrm{N}_{2}$ and $\mathrm{O}_{2}$ are only generated owing to a moderately high rate of $\mathrm{AN}$ disintegration, however since AN deterioration wanes along the FR, the reaction rate of $\mathrm{O}_{2}$ and $\mathrm{N}_{2}$ is diminished. 


\section{Chemical Engineering Research Bulletin 20(2018) 8-18}

Furthermore, oxidation of $\mathrm{N}_{2}$ prompts more diminished of $\mathrm{O}_{2}$ and $\mathrm{N}_{2}$ at whatever is left of the reactor. In this way, the groupings of $\mathrm{O}_{2}$ and $\mathrm{N}_{2}$ increment at the beginning sections of the reaction zone, however then decreasing gradually. As found in Figures 7 and 8, the concentration $\mathrm{s}$ of $\mathrm{O}_{2}$ and $\mathrm{N}_{2}$ have an expanding pattern in the bubble phase along the reaction zone. As specified already, the AN decay rate is unimportant in the bubble phase, so accordingly, $\mathrm{O}_{2}$ and $\mathrm{N}_{2}$ will not be generated and their expanding content in the bubble phase is just identified with mass exchange among such phases. In other words, since the fluid phase and air are combined to spray fluid to the FB, a few amounts of air is entered to the bubble phase. Thus, the initial concentration of $\mathrm{N}_{2}$ and $\mathrm{O}_{2}$ would not be zero in such phases as appeared in these Figures. The concentration of $\mathrm{H}_{2} \mathrm{O}$ that is generated during $\mathrm{AN}$ decay is unique in relation to that of $\mathrm{O}_{2}$ and $\mathrm{N}_{2}$. The initial concentration of $\mathrm{H}_{2} \mathrm{O}$ is zero as delineated in Figure 9 in light of the fact that the input air in the fluidized reactor has assumed to be dry. At the first part of the reaction zone, $\mathrm{H}_{2} \mathrm{O}$ is generated at a significantly higher rate because of extensive disintegration of $\mathrm{AN}$ in the first sections of the reaction zone.

\section{Optimal Operation Results (Case 2)}

The developed mathematical model here can now be confidently utilized for obtaining the optimal operating conditions employing the objective function explained previously with satisfying all the equality and inequality constraints. Where, the optimum operating conditions (initial concentration of AN $\left(C_{A N O}\right)$, bed temperature $(T)$ and gas velocity $\left(u_{g}\right)$ ) for minimization of $\mathrm{AN}$ and NO content in the product of the fluidized bed reactor are obtained. As mentioned previously, such process variables having a significant impact upon the process conversion. The optimal operating conditions of ANTD (case study 2) are listed in Table 3.

As clearly observed depending on the results presented in this Table, the main goal of this study for the purpose of obtaining an environmentally friendly reactor design of AN thermal decomposition has been achieved. Where, the output conversion of ammonium nitrate at the optimal design parameters (the optimal initial concentration of ammonium nitrate $\left(C_{A N O}\right)=189.52\left(\mathrm{Kg} / \mathrm{m}^{3}\right)$, the optimal bed temperature $(T)=381.42\left({ }^{\circ} \mathrm{C}\right)$, optimal gas velocity $\left(u_{g}\right)=5.76 \mathrm{U}_{\mathrm{m}}(\mathrm{m} / \mathrm{s})$ obtained via optimization process has optimized to be $100 \%$ (zero content of AN in the product) with minimum concentration of $\mathrm{NO}$ at $0.0197 \mathrm{Kg} / \mathrm{m}^{3}$.
Table 3: Optimal results for case study 2

\begin{tabular}{|l|l|}
\hline \multicolumn{1}{|c|}{ Parameters } & \multicolumn{1}{|c|}{ Optimal Values } \\
\hline $\begin{array}{l}\text { Optimal initial concentration } \\
\text { of ammonium nitrate }\left(C_{A N O}\right)\end{array}$ & $189.52\left(\mathrm{Kg} / \mathrm{m}^{3}\right)$ \\
\hline Optimal bed temperature $(T)$ & $381.42\left({ }^{\circ} \mathrm{C}\right)$ \\
\hline Optimal gas velocity $\left(u_{g}\right)$ & $5.76 \mathrm{U}_{\mathrm{m}}(\mathrm{m} / \mathrm{s})$ \\
\hline $\begin{array}{l}\text { Minimum concentration of } \\
\text { nitrogen oxide }\end{array}$ & $\mathbf{0 . 0 1 9 7}\left(\mathbf{K g} / \mathbf{m}^{3}\right)$ \\
\hline $\begin{array}{l}\text { The output conversion of } \\
\text { AN at optimal conditions }\end{array}$ & $\mathbf{1 0 0 . 0 0}(\%)$ \\
\hline
\end{tabular}

A comparison between the concentration profile of ammonium nitrate along the reaction zone length using case $1\left(\mathrm{~T}=350{ }^{\circ} \mathrm{C}\right.$, initial concentration $=150$ $\mathrm{Kg} / \mathrm{m}^{3}$ and $\mathrm{u}_{\mathrm{g}} / \mathrm{u}_{\mathrm{m}}=7$ ), and nitrogen oxide along the reaction zone length using case 2 (optimal fluidized reactor) utilizing the optimal operating conditions $\left(\mathrm{T}=381.42{ }^{\circ} \mathrm{C}\right.$, initial concentration of $\mathrm{AN}=189.52$ $\mathrm{Kg} / \mathrm{m}^{3}$ and $\mathrm{u}_{\mathrm{g}} / \mathrm{u}_{\mathrm{m}}=5.76$ ) is described in Figure 10 and reported in Table 4 (compared with those reported with last studies).

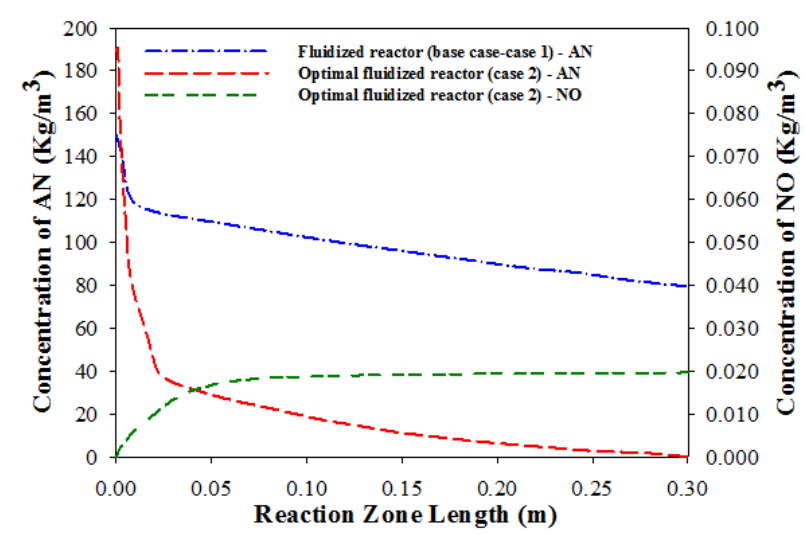

Figure10: Concentration profile of $\mathrm{AN}$ along reaction zone length using case $1\left(\mathrm{~T}=350{ }^{\circ} \mathrm{C}\right.$, initial concentration $=150 \mathrm{Kg} / \mathrm{m}^{3}$ and $\left.\mathrm{u}_{\mathrm{g}} / \mathrm{u}_{\mathrm{m}}=7\right)$, and $\mathrm{AN}$ and NO by using case 2 utilizing the optimal operating conditions $\left(\mathrm{T}=381.42^{\circ} \mathrm{C}\right.$, initial concentration of AN $=189.52 \mathrm{Kg} / \mathrm{m}^{3}$ and $\left.\mathrm{u}_{\mathrm{g}} / \mathrm{u}_{\mathrm{m}}=5.76\right)$

It has been noticed from these results that the optimized fluidized reactor for the conversion of ammonium nitrate and minimizing nitrogen oxide concentration has improved by using the modified operating conditions giving the highest conversion of AN (100\%) in comparison with those obtained by last studies due to the modified kinetic parameters, which are playing an important key factors in design operations. Also, these results can be attributed to the new approach (successive quadratic programming) utilized in this work for minimizing the concentration of AN and NO in the products based on the modified kinetic parameters, which is better than the methods used with all last studies that employed different 


\section{Chemical Engineering Research Bulletin 20(2018) 8-18}

Table 4: Comparison results between this study and last studies

\begin{tabular}{|c|c|c|c|c|}
\hline Authors (year) & Solution Method & $\begin{array}{c}\text { Sum of Square } \\
\text { Errors (Based } \\
\text { on Case 1) }\end{array}$ & \multicolumn{2}{|c|}{$\begin{array}{l}\text { Output Concentration of AN } \\
\text { and NO in the Product } \\
\text { (Using Case } 2 \text { here) }\end{array}$} \\
\hline \multirow[t]{2}{*}{ Bhowmick et al. (2012) ${ }^{1}$} & \multirow{2}{*}{$\begin{array}{c}4^{\text {th }} \text { Runge-Kutta } \\
\text { (R-K) }\end{array}$} & \multirow[t]{2}{*}{$228.305^{*}$} & $\mathrm{AN}\left(\mathrm{Kg} / \mathrm{m}^{3}\right)$ & $\mathrm{NO}\left(\mathrm{Kg} / \mathrm{m}^{3}\right)$ \\
\hline & & & 15.0 & Not Studied \\
\hline Mirvakili et al. (2013) ${ }^{2}$ using OCFFDR & BFD & $90.276^{*}$ & 3.0 & 0.006 \\
\hline Mirvakili et al. (2013) ${ }^{2}$ using MFR & $\begin{array}{l}\text { Backward Finite } \\
\text { Difference and } \\
\text { Gauss-Newton }\end{array}$ & $141.430 *$ & $\begin{array}{c}\text { Not } \\
\text { Reported }\end{array}$ & 0.9486 \\
\hline Mirvakili et al. (2014) ${ }^{12}$ using AMFR & BFD - GN & $207.184 *$ & $\begin{array}{c}\text { Not } \\
\text { Reported }\end{array}$ & 0.8568 \\
\hline Mirvakili et al. $(2015)^{3}$ using FR & $\mathrm{DE}$ & $90.276^{*}$ & 0.21 & 1.02 \\
\hline This study (2018) & SQP & 0.8066 & 0.00 & 0.0197 \\
\hline
\end{tabular}

* the value has been estimated

solvers to minimize the objective function to obtain the optimal design of fluidized bed reactor for such reaction. As well as, the SQP method utilized in this work having a high accuracy in determining the decision variables of the process (advanced solver and formalisms for model improvement that permit to characterize the complex models sufficiently and has numerous properties, which make it an active tool and helpful for the modelling, simulation and optimization of any design process). Also, this strategy is an exceedingly confided way for solving of such mathematical models.

\section{Conclusion}

The optimal design of an environmentally friendly reactor for ammonium nitrate thermal decomposition has been investigated here via developing the design factors of such operation for the purpose of boosting the process conversion by firstly adjusting the kinetic parameters and then improving the operating conditions. An optimization framework has improved in order to tackle the optimum design and operation problem of such reactor. Where, the kinetic parameters of the relevant reactions were achieved using the optimization technique to construct the model with high accuracy based on experiments (with AAE less that $1 \%$ among all results between the experimental results and predicted data). Then, such kinetic factors were utilized to obtain the best operating conditions of the operation via developing the design factors. The mathematical model modified along the reaction zone length of ammonium nitrate decomposition have used to predict the concentration of all components in bubble and emulsion phases in addition to the axial temperature profile of the gas phase. The results of the modified kinetic parameters have clearly indicated that estimation of kinetic parameters accurately based on experiments can improve the design factors and plays a significant issue in such operations. A new results in comparison with those reported in the literature related to the AN thermal decomposition, and ammonium nitrate-free content in the products with the highest conversion $(100 \%)$ and minimizing the amount of NO (as two environmental hazards), have been obtained.

\section{References}

1. S. Bhowmick, H. Rao and D. Sathiyamoorthy, "Thermal denitration of ammonium nitrate solution in a fluidized-bed reactor," Industrial \& Engineering Chemistry Research, vol. 51, no. 25. pp. 8394-8403, 2012.

2. A. Mirvakili, S. Bahrani and A. Jahanmiri, "An Environmentally Friendly Configuration for Ammonium Nitrate Decomposition," Industrial \& Engineering Chemistry Research, vol. 52, no. 37. pp. 13276-13287, 2013.

3. A. Mirvakili, F. Samimi and A. Jahanmiri, "Optimization of Ammonium Nitrate Thermal Decomposition in a Fluidized Bed Reactor Using Differential Evolution (DE) Method," Chemical Engineering Communications, vol. 202, no. 5. pp. 557-568, 2015.

4. D.-W. Cho, C.-M. Chon, Y. Kim, B.-H. Jeon, F. W. Schwartz, E.-S. Lee and H. Song, "Adsorption of nitrate and $\mathrm{Cr}$ (VI) by cationic polymer-modified granular activated carbon," Chemical Engineering Journal, vol. 175, pp. 298-305, 2011.

5. Y. F. Nava, E. Marann, J. Soons and L. Castrilln, "Denitrification of high nitrate 


\section{Chemical Engineering Research Bulletin 20(2018) 8-18}

concentration wastewater using alternative carbon sources," Journal of Hazardous Materials, vol. 173, no. 1-3. pp. 682-688, 2010.

6. M. Kurt, I. J. Dunn and J. R. Bourne, "Biological denitrification of drinking water using autotrophic organisms with $\mathrm{H}_{2}$ in a fluidized-bed biofilm reactor," Biotechnology and Bioengineering, vol. 29, no. 4. pp. 493-501, 1987.

7. D. Dries, J. Liessens, W. Verstraete, P. Stevens, P. Vost, and J. Ley, "Nitrate removal from drinking water by means of hydrogenotrophic denitrifiers in a polyurethane carrier reactor," Water Supply, vol. 6, no. 3. pp. 181-192, 1988.

8. H. Gros, G. Schnoor and P. Rutten, "Biological denitrification process with hydrogen oxidizing bacteria for drinking water treatment," Water Supply, vol. 6: pp. 193-198, 1986.

9. C. C. Chang, S. K. Tseng and H. K. Huang, "Hydrogenotrophic denitrification with immobilized Alcaligenes eutrophus for drinking water treatment," Bioresource Technology, vol. 69, no. 1. pp. 53-58, 1999.

10. S. Szekeres, I. Kiss, T. T. Bejerano and M. I. M. Soares, "Hydrogen-dependent denitrification in a two-reactor bio-electro-chemical system," Water Research, vol. 35, no. 3. pp. 715-719, 2001.

11. I. A. Vasiliadoua, K. A. Karanasiosa, S. Pavloubc and D. V. Vayenas, "Experimental and modelling study of drinking water hydrogenotrophic denitrification in packed-bed reactors," Journal of Hazardous Materials, vol. 165, no. 1-3. pp. 812-824, 2009.

12. A. Mirvakili, F. Samimi and A. Jahanmiri, "Simultaneous ammonium nitrate decomposition and $\mathrm{NO}_{\mathrm{x}}$ emission reduction in a novel configuration of membrane reactor: A simulation study," Journal of Industrial and Engineering Chemistry, vol. 20, no. 4. pp. 2452-2462, 2014.

13. A. T. Nawaf, A. T. Jarullah, A. G. Saba and I. M. Mujtaba, "Development of Kinetic and Process Models for the Oxidative Desulfurization of Light Fuel, Using Experiments and the Parameter Estimation Technique," Industrial \& Engineering Chemistry Research, vol. 54, no. 50. pp. 1250312515, 2015.

14. A. E. Mohammed, A. T. Jarullah, A. G. Saba and I. M. Mujtaba, "Optimal design and operation of an industrial three phase reactor for phenol oxidation," Computers \& Chemical Engineering, vol. 94: pp. 257-271, 2016.

15. L. Peng and J. Zhang, "Simulation of turbulent combustion and NO formation in a swirl combustor," Chemical Engineering Science, vol. 160, no. 12. pp. 2903-2914, 2009.

16. R. C. Reid, J. M. Prausnitz and B. E. Poling, The Properties of gases \& liquids, $4^{\text {th }}$ edition, McGraw-Hill: New York, 1987.

17. D. Kunii and O. Levenspiel, Fluidization Engineering, Wiley: New York, 1991.

18. W.-Z. Lu, L.-H. Teng, and W.-D. Xiao, "Simulation of turbulent combustion and NO formation in a swirl combustor," Chemical Engineering Science, vol. 59, no. 12. pp. 54555464, 2004.

19. H. J. Subramani, M. B. M. Balaiyya and L. R. Miranda, "Minimum fluidization velocity at elevated temperature for Geldart's group-B powders," Experimental Thermal Fluid Science, vol. 32, no. 1. pp. 166-173, 2007.

20. P. Cai, M. Schiavetti, G. De Michele, G. Grazzini and M. Miccio, "Quantitative estimation of bubble size in PFBC," Powder Technology, vol. 80, no. 2. pp. 99-109, 1999.

21. J. F. Davidson and D. Harrison, Fluidized Particles, Cambridge University Press: Cambridge, UK, 1963.

22. C. R. Wilke and C. Y. Lee, "Estimation of Diffusion Coefficients for Gases and Vapors," Industrial and Engineering Chemistry, vol. 47, no. 6. pp. 1253-1257, 1955.

23. C. Gau and M. A. Stadtherr, "Reliable Nonlinear Parameter Estimation Using Interval Analysis: Error-in-Variable Approach," Computers \& Chemical Engineering, vol. 24, no. 2-7. pp. 631-637, 2000.

24. A. T. Jarullah, I. M. Mujtaba and S. W. Alastair, "Kinetic parameter estimation and simulation of trickle-bed reactor for hydrodesulfurization of crude oil," Chemical Engineering Science, vol. 66, no. 5. pp. 859-871, 2011.

Publisher: Department of Chemical Engineering, Bangladesh University of Engineering and Technology (BUET). Review \&Publication: A submitted original manuscript is taken into review only if the uniqueness is found to be more than $85 \%$ in plag-scanning and selected for publication by the complete acceptance from at least two reviewers out of three. Home Page: http://www.banglajol.info/index.php/CERB. Indexed by Chemical Abstract Service (CAS), CEABA-VtB, Google Scholar, Scopus and DOAJ. 